\title{
LEVANTAMENTO E IDENTIFICAÇÃO DE CUPINS (INSECTA: ISOPTERA) EM ÁREA URBANA DE PIRACICABA - SP
}

\section{SURVEY AND IDENTIFICATION OF TERMITES (INSECTA: ISOPTERA) IN A URBAN AREA OF PIRACICABA, STATE OF SÃO PAULO, BRAZIL}

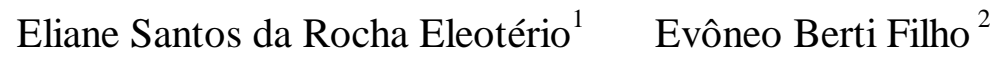

\section{RESUMO}

Este trabalho foi realizado com o objetivo de fazer um estudo de ocorrência de cupins no Bairro São Dimas, na cidade de Piracicaba, São Paulo, realizando o levantamento e a identificação das espécies de cupins presentes nas edificações, visando a determinar as espécies de cupins mais freqüentes e a estabelecer a relação entre ocorrência de cupins e a idade das edificações. Os imóveis foram selecionados por amostragem, sendo que as espécies mais encontradas, infestando as edificações foram: o cupim de madeira seca Cryptotermes brevis (Walker) e o cupim subterrâneo Coptotermes havilandi (Holmgren). Constatou-se que o risco de infestações por cupins, bem como número de focos por edificação tendem a aumentar com a idade das construções.

Palavras-chave: Biodeterioração, cupins, idades das edificações, área urbana.

\begin{abstract}
This paper deals with the occurrence of termites in a urban area of Piracicaba City, State of São Paulo, Brazil. Samples of home and commercial buildings were surveyed and the termites collected were identified. The most frequent species were the drywood termite, Cryptotermes brevis, and the subterranean termite, Coptotermes havilandi. It was observed that the risk of termite attacks, as well as the number of attacks per building showed a tendency to increase with the age of the buildings.
\end{abstract}

Key words: Biodeterioration, termites, building ages, urban area.

\section{INTRODUÇÃO}

Contrapondo-se a inúmeras vantagens apresentadas pela madeira e seus derivados, determinantes para a sua ampla utilização, existe a biodeterioração, pois segundo OLIVEIRA et al. (1986), a madeira é um material de origem orgânica e como tal está sujeita à deterioração por

1. Bióloga, Aluna do Curso de Pós-Graduação (Mestrado) em Ciência e Tecnologia de Madeiras, Departamento de Ciências Florestais, ESALQ/USP, CEP 13418-900, Piracicaba (SP).

2. Engenheiro Agrônomo, Professor Titular do Departamento de Entomologia, Fitopatologia e Zoologia Agrícola. ESALQ/USP, CEP 13418-900, Piracicaba (SP). 
agentes biológicos (fungos, insetos e brocas marinhas).

Os organismos biodeterioradores apresentam características morfológicas, fisiológicas e comportamentais especiais que os tornam capazes de utilizar a madeira como substrato, abrigo e alimento. Nesse contexto, destaque especial é dado aos cupins ou térmitas que, por causa da capacidade de digerir celulose proporcionada por fauna microbiológica simbionte presente em seu intestino, são atraídos por todo o material de origem celulósica, como a madeira em seu estado bruto, papel, tecidos e outros (GRASSÉ, 1982; OLIVEIRA et al., 1986).

Os danos causados, por cupins em construções, trazem enormes prejuízos, pois, de maneira geral, são percebidos quando já causaram grande comprometimento estrutural. Os custos, com o controle curativo e recuperação das construções, é alto. No Brasil, existem poucas espécies de cupins considerados prejudiciais cuja biologia é pouco conhecida, por isso, EDWARDS \& MILL (1986), LELIS (1995) e WALLER \& LA FAGE (1986) reforçam que se tornou de grande necessidade a realização de estudos que contribuam para o conhecimento da biologia desses insetos, sobre as principais espécies que causam danos em áreas urbanas, bem como sobre as que apresentam potencial de se tornarem pragas, e a sua distribuição.

Apesar dos térmitas pertencerem a um dos grupos animais mais bem-sucedidos do planeta, poucas espécies têm tido sucesso na transição do ambiente natural para o ambiente urbano e o sucesso de algumas espécies tem sido relacionado a sua habilidade em se adaptar às mais variadas condições existentes em meio urbano (ROBINSON, 1996).

WALLER \& LA FAGE (1986) acreditam que a eliminação de competição e a eliminação dos predadores pelo homem facilitaram a proliferação dos térmites em áreas urbanas.

Segundo LELIS (1999), a densidade e a proximidade das edificações em grandes cidades, como ocorre em São Paulo, facilitam a infestação por cupins subterrâneos que estão presentes em árvores de praças e jardins e em grandes parques.

No Brasil, os ataques mais freqüentes às edificações urbanas têm sido ocasionados por cupins pertencentes a dois grupos: cupins subterrâneos e cupins de madeira seca (LELIS, 1976).

As colônias de cupins de madeira seca, segundo MARER (1991), pertencem à família Kalotermitidae e infestam madeira seca, não-apodrecida, estrutural, móveis, ramos de árvores vivas em locais sombreados, árvores em pomares, postes e madeiras armazenadas. Com base nessas áreas, reprodutores alados migram para novas construções e outras estruturas em dias ensolarados nos meses chuvosos. Segundo o autor, as colônias desses cupins geralmente são pequenas e são capazes de viver em pequenas peças de madeira que podem ser acidentalmente transportados pelo homem implicando na sua ampla área de distribuição.

Os cupins pertencentes a esse grupo têm baixo requerimento de umidade e possuem grande tolerância às condições secas por períodos prolongados. A água pode ser obtida diretamente da madeira que, mesmo sendo em pequena quantidade é o suficiente graças a mecanismos especiais desenvolvidos para reduzir a perda de água (EDWARDS \& MILL, 1986; WALLER \& LA FAGE, 1986 e RUDOLPH et al., 1990).

Dentre os cupins de madeira seca, as espécies que mais causam danos no mundo pertencem 
ao gênero Cryptotermes, sendo que, no Brasil, Cryptotermes brevis é citada como praga importante (ARAÚJO, 1980).

STEWARD (1983) comparou Cryptotermes brevis com outras espécies de cupins do mesmo grupo e constatou que essa espécie sobrevive melhor tanto em condições quentes-secas como em frias-úmidas e sua ampla distribuição no planeta pode estar relacionada à sua habilidade de submeterse a aclimatação e de alimentar-se eficientemente em umidades relativas tanto médias (cerca de 60\%) como altas (cerca de 90\%).

Os cupins chamados de subterrâneos pertencem à família Rhinotermitidae e segundo ARAÚJO (1980), BANDEIRA (1989), EDWARDS \& MILL (1986), HARRIS (1971), LELIS (1995), MARICONI et al. (1980), os pertencentes ao gênero Coptotermes são os que causam maiores prejuízos em edificações urbanas de outros países e de várias regiões do Brasil.

No Brasil, a citada como a causadora de danos mais expressivos em construções na Região Sudeste é a espécie oriental Coptotermes havilandi (FONTES, 1995).

A necessidade de água dos cupins subterrâneos é grande e eles necessitam de fontes disponíveis de umidade, sendo que em pesquisa realizada com espécies de Rhinotermitidae, Mastotermitidae e Nasutitermes nigriceps, foi verificado que os cupins detectam rapidamente a água oferecida e logo em seguida a bebem, comprovando a sua grande necessidade de água (RUDOLPH et al. (1990).

Esta pesquisa teve como objetivo fazer um estudo de ocorrência de cupins no bairro São Dimas, na cidade de Piracicaba, São Paulo, realizando o levantamento e a identificação das espécies de cupins presentes nas edificações, visando a determinar as espécies de cupins mais freqüentes e a estabelecer a relação entre ocorrência de cupins e a idade das edificações.

\section{MATERIAL E MÉTODOS}

Este trabalho foi realizado no bairro São Dimas, em Piracicaba, estado de São Paulo $\left(22^{0} 42^{\prime}\right.$ 30" S de latitude e a $47^{\circ} 38^{\prime} 01$ " W de longitude, com altitude de $554 \mathrm{~m}$ ) Os fatores que determinaram a escolha do bairro São Dimas para a realização deste estudo foram: ter histórico anterior de presença de cupins, contar com edificações de idades bastante variadas, tanto antigas quanto novas, de estilos e técnicas construtivas distintas e estar localizado próximo ao campus universitário, possibilitando rapidez e facilidade de acesso. A temperatura máxima registrada é 37, $5^{\circ}$ C e a mais baixa é $18,0^{\circ} \mathrm{C}$. Piracicaba é a $19^{\text {a }}$ cidade do estado de São Paulo em extensão territorial, com área total de $1.312,3 \mathrm{~km}^{2}$, dos quais $158,06 \mathrm{~km}^{2}$ são de área urbana. Na cidade há 74.759 imóveis residenciais e 6.907 imóveis comerciais. No bairro São Dimas, de acordo com a Prefeitura Municipal de Piracicaba, existem 2.451 imóveis residenciais e 197 imóveis comerciais (CIAGRI, 1999).

Foram sorteadas, aleatoriamente, 10 quadras de um total de 107. Em cada quadra foi feito um levantamento que visou a verificar o número de edificações existentes e para que fins eram utilizadas (residência ou comércio). Desse levantamento, foram definidos os estratos a serem 
estudados para facilitar a análise estatística dos resultados: edificações residenciais e comerciais. Determinou-se o número de prédios de apartamentos existentes em todo o bairro, a fim de verificar a necessidade da criação de mais um estrato. Constatando-se que eram poucos os prédios de apartamentos existentes no bairro, todos foram inspecionados e considerados como um estrato à parte. Para a determinação de quais edificações residenciais seriam inspecionadas, foi realizado um sorteio aleatório de 4 edificações por quadra.

Foi determinado, previamente às inspeções, que na impossibilidade de se realizar a visita a um dos imóveis sorteados, o próximo à sua direita o substituiria, se esse também não fosse possível ser visitado, o próximo à esquerda do imóvel preferencial para a amostragem o substituiria e assim sucessivamente. Constatando-se, no levantamento da utilização dos imóveis nas quadras, que as edificações comerciais eram em pequeno número, todas foram consideradas na amostragem.

As edificações e seus móveis foram examinados quanto à presença de cupins e idade.

Alguns prédios possuíam mais de um piso construídos abaixo do andar térreo, e os exames foram iniciados com base no "subsolo" inferior. Foram verificados: casas de bombas, salas dos quadros de medição, juntas de dilatação, aberturas para passagem de eletrodutos e cabos telefônicos, bocas de lobo, aberturas das tubulações para o escoamento de excesso de água, aberturas para o sistema de esgoto, poços dos elevadores, salas para utensílios de materiais de manutenção e salas de depósitos dos condôminos. No térreo dos prédios de apartamentos estão localizados, a recepção, salão de festas e de jogos, sauna, piscina, banheiros e cozinhas coletivos. No térreo, foram verificados: piso, forro e balcões, bem como mobiliário, pilares e portas. Na piscina, foi verificada a casa de bombas e de filtros e eventual local para depósito de materiais. Além da parte interna da edificação, também foram examinados os jardins. Na cobertura, foram inspecionadas a caixa de água e a casa de máquinas dos elevadores.

Nas edificações residenciais, foram feitas observações internas (porão, forros, pisos, portas e janelas) e externas (portas e janelas), edículas, lavanderias e varandas.

Os prédios comerciais foram inspecionados segundo os mesmos critérios utilizados para os prédios residenciais. Foi dada, no entanto, atenção especial aos materiais utilizados na divisão de cômodos (divisórias e móveis) e que não existiam em prédios residenciais.

Nas inspeções, foram procuradas evidências da presença de cupins subterrâneos e/ou de madeira seca. A presença de galerias, que os cupins subterrâneos constróem para se deslocar pela construção, foram consideradas a principal prova de sua presença. Em locais escuros, tais evidências foram procuradas com o auxílio de lanterna, para melhor visualização dos locais menos acessíveis (porões e locais sem utilização constante). Pinça anatômica e chave de fenda foram empregadas para testar a presença de galerias internas em peças de madeira e para abrir pequenos vãos entre juntas de dilatação para a verificação da presença de trilhas de forrageamento. Ao constatar a infestação por cupins subterrâneos, o local, onde foram localizados os indícios de sua presença, foi inspecionado com maior rigor, a fim de coletar o cupim infestante para identificação. Os dados foram anotados em fichas individuais, para imóvel e móveis, para posterior agrupamento e análise.

Quanto aos cupins de madeira seca, as observações foram direcionadas para a presença de orifícios na superfície de peças e estruturas de madeira e móveis e para a localização de grânulos 
fecais. Também utilizou-se uma lanterna para obter visualização mais clara da peça. Pinça e chave de fenda foram utilizadas para testar a presença de galerias internas nos batentes de portas e janelas e de outras peças, no caso de terem sido verificados previamente sinais da presença desses cupins (grânulos fecais e/ou orifícios). Foram coletados, quando possível, cupins que infestavam estruturas de madeira (soldados e operários) e colocados em recipientes com álcool a 70\%. Quando não foi possível encontrar os cupins coletou-se os resíduos deixados por eles (grânulos fecais). Essas amostras foram utilizadas para a identificação do agente causador da infestação. Os dados foram anotados em fichas individuais, para imóvel e móveis para posterior agrupamento e análise.

Os cupins coletados foram observados em microscópio eletrônico de varredura de pressão variável (MEV LEO 435 VP) em alto vácuo. Para tanto, foram retirados do álcool a 70\%, secos ao ar por 15 minutos, dispostos em "stubs" sobre fita de carbono dupla face e metalizados por 180 segundos. Os grânulos fecais foram colocados em fita de carbono dupla face e metalizados por 180 segundos, sendo logo após observados em microscópio de varredura em alto vácuo. Dessa forma, pôde-se identificar a família a qual pertencem os cupins causadores do ataque.

\section{Análise dos dados}

Os dados foram analisados quanto à ocorrência de cupins de madeira seca e subterrâneos e seus percentuais, em relação ao total de construções inspecionadas, levando-se em conta as espécies de cupins encontradas e a ocorrência de cupins de madeira seca e subterrâneos simultaneamente. Procurou-se estabelecer correlação entre a ocorrência de cupins e a idade da construção, aplicandose o coeficiente de correlação linear de Pearson.

\section{RESULTADOS E DISCUSSÃO}

Os resultados, da mesma forma que a amostragem, são apresentados separados em três estratos: edificações residenciais, comerciais e prédios de apartamentos. Os fatores que influenciam o ataque dos cupins são discutidos por estrato.

\section{Estrato 1 - Residências}

\section{Edificação}

As idades das edificações visitadas, variaram entre 0 e 90 anos, sendo que 47,5\% estavam entre 15 e 30 anos. Esses resultados demonstram a variabilidade de idades dentro do bairro o que influenciou na sua escolha para a realização deste trabalho.

Verificou-se que há uma tendência em aumentar a probabilidade de infestações por cupins com a idade da edificação (Tabela 1). Em edificações novas, de 0 a 15 anos, nenhuma apresentou ataque por cupins, em edificações de 15 a 30 anos, 36,8\% apresentaram cupins e em edificações entre 30 a 45 anos, 75,0\% apresentaram cupins. Nas faixas restantes de idade, de 45 a 60 anos, de 60 a 75 anos e de 75 a 90 anos todos os imóveis apresentaram cupins em alguma parte da sua construção. Comparando esses resultados pelo teste de $\chi^{2}$, conclui-se que as diferenças são 
significativas.

TABELA 1: Distribuição das freqüências absolutas e relativas das ocorrências de cupins em edificações residenciais agrupadas em classes de idades ( $A=$ porcentagem dentro da classe; $\mathrm{B}=$ porcentagem sobre o total de edificações amostradas).

\begin{tabular}{|c|c|c|c|c|c|c|c|}
\hline $\begin{array}{c}\text { Classes de Idade } \\
\text { (anos) }\end{array}$ & $\begin{array}{c}\text { Com } \\
\text { Cupins }\end{array}$ & $\begin{array}{c}\text { A } \\
(\%) \\
\end{array}$ & $\begin{array}{c}\text { Sem } \\
\text { Cupins }\end{array}$ & $\begin{array}{c}\mathrm{A} \\
(\%)\end{array}$ & Total & $\begin{array}{l}\mathrm{B} \\
(\%)\end{array}$ & $\chi^{2}$ \\
\hline $0-15$ & 0 & 0 & 5 & 100,0 & 5 & 12,5 & \\
\hline $16-30$ & 7 & 36,8 & 12 & 63,2 & 19 & 47,5 & \\
\hline $31-45$ & 6 & 75,0 & 2 & 25,0 & 8 & 20,0 & \\
\hline $46-60$ & 2 & 100,0 & 0 & 0 & 2 & 5,0 & \\
\hline $61-75$ & 1 & 100,0 & 0 & 0 & 1 & 2,5 & \\
\hline \multirow[t]{2}{*}{$76-90$} & 5 & 100,0 & 0 & 0 & 5 & 12,5 & \\
\hline & 21 & 52,5 & 19 & 47,5 & & & $15,41 * *$ \\
\hline
\end{tabular}

Em que: $* * \mathrm{gl}=5 ; \alpha=1 \%$

O aumento, na probabilidade de ataque de cupins com a idade dos imóveis, pode ser resultado do maior período de exposição dessas edificações às revoadas. GOLD et al. (1996) constataram, estudando ocorrência de cupins em áreas costeiras do Texas, que em estruturas de mais de 40 anos de idade a probabilidade de infestação por uma ou mais espécies de cupins é superior a $90 \%$.

Também se pode considerar o desgaste da edificação e a falta de manutenção do tempo, como fatores que contribuem para o estabelecimento de infestações de cupins.

\section{Número de focos e idade das edificações}

O número total de edificações, com ocorrências de cupins, é 21, sendo que uma edificação pode apresentar mais de um foco de cupins. Foi feita a análise da relação entre a idade da edificação e o número de focos de cupins por edificação (Figura 1).

A correlação entre o número de focos e a idade das edificações, expressa pelo coeficiente de correlação de Pearson, é de $67 \%$. No entanto, deve ser considerada a existência de outros fatores que também influenciam no estabelecimento das colônias e que não foram mensurados neste estudo.

\section{Móveis}

Dentre as quarenta edificações visitadas, foram encontrados 28 móveis infestados por cupins de madeira seca, distribuídos em dezoito edificações.

\section{Análise conjunta das edificações e móveis}

Considerando-se todas as edificações inspecionadas, pode-se separá-las em três grupos: as que apresentaram cupins tanto em peças da construção como em móveis, em número de onze $(27,5 \%)$, as que apresentaram cupins apenas na edificação, em número de dez $(25,0 \%)$ ou apenas 
nos móveis sete $(17,5 \%)$ e as que não apresentaram focos de cupins, dezenove $(47,5 \%)$. Dessa forma, a presença de cupins na edificação não implica necessariamente em infestação dos móveis e vice-versa. Possivelmente esse resultado se deve às diferentes características existentes entre os móveis e os imóveis. Dentre elas, pode-se citar, tipo de material, tipo de acabamento (pintura) e diferentes condições de umidade, entre outros.

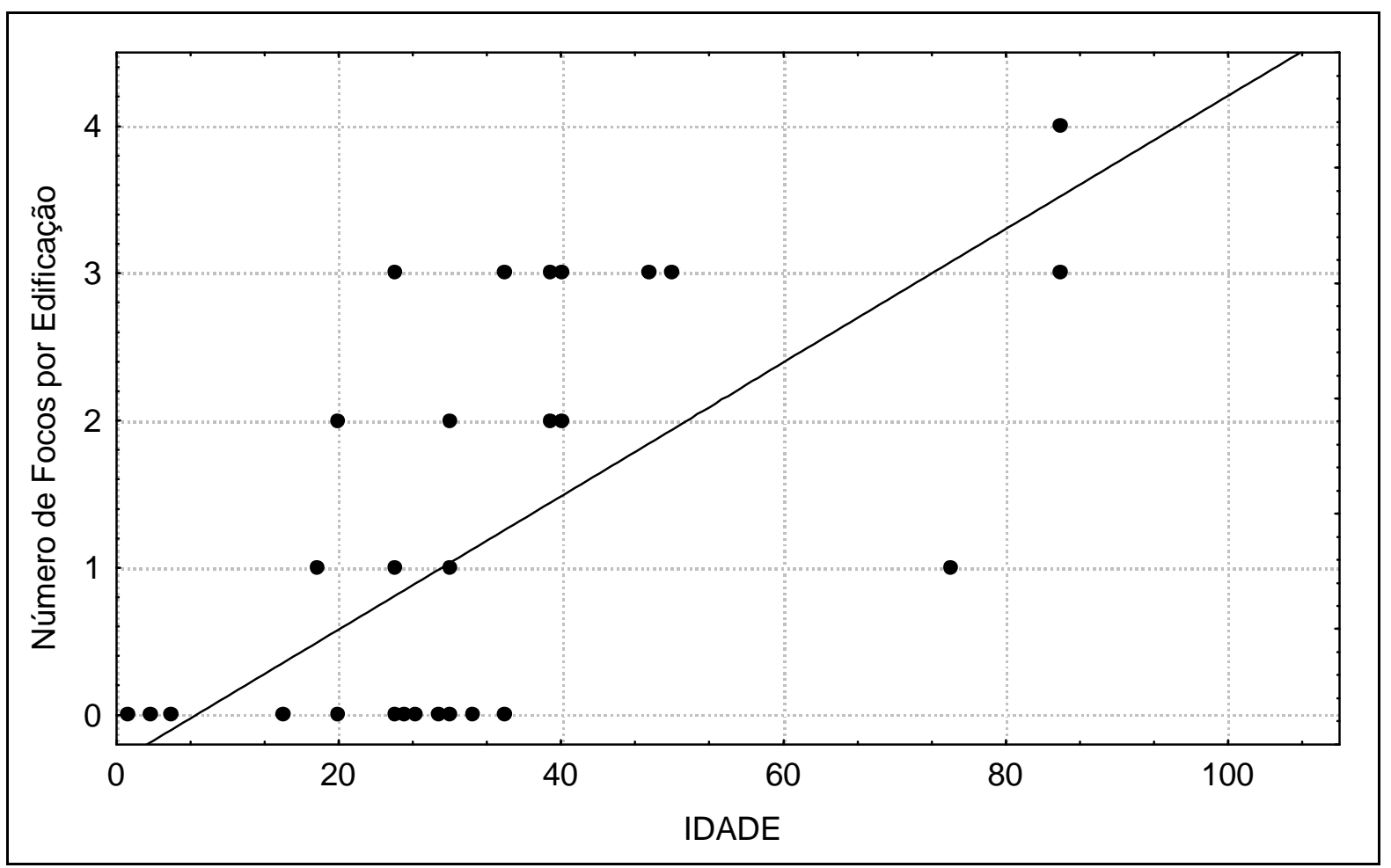

FIGURA 1: Relação entre idade das edificações e número de focos de cupins.

\section{Estrato 2 - Comerciais}

\section{Edificação}

As idades das edificações comerciais visitadas variaram entre 0 e 70 anos, sendo que $25 \%$ estavam entre quinze e trinta anos. Verificou-se que, em edificações novas, de 0 a 15 anos, apenas $16,6 \%$ apresentaram cupins, contra 25,0\% dessa classe nas quais não houve ocorrência de cupins. Na classe de 16 a 30 anos, essa proporção se inverte: $25,0 \%$ delas apresentaram cupins e 16,6\% não apresentaram (Tabela 2).

Considerando-se apenas as duas primeiras classes de idades, pode-se dizer que a probabilidade de infestações por cupins tende a aumentar com a idade da edificação, mas essa relação não é clara, dado ao reduzido número de amostras. 
TABELA 2: Distribuição das frequiências absolutas e relativas das ocorrências de cupins em edificações comerciais agrupadas em classes de idades $(\mathrm{A}=$ porcentagem dentro da classe; $\mathrm{B}=$ porcentagem sobre o total de residências amostradas).

\begin{tabular}{l|c|c|c|c|c}
\hline $\begin{array}{c}\text { Classes por idades } \\
(\text { anos })\end{array}$ & $\begin{array}{c}\text { Com } \\
\text { Cupins }\end{array}$ & $\begin{array}{c}\text { A } \\
(\%)\end{array}$ & $\begin{array}{c}\text { Sem } \\
\text { Cupins }\end{array}$ & $\begin{array}{c}\text { A } \\
(\%)\end{array}$ & $\begin{array}{c}\text { B } \\
(\%)\end{array}$ \\
\hline $0-15$ & 2 & 40,0 & 3 & 60,0 & 41,6 \\
$16-30$ & 3 & 60,0 & 2 & 40,0 & 41,6 \\
$31-45$ & 0 & 0 & 1 & 100,0 & 8,4 \\
$46-70$ & 1 & 100,0 & 0 & 0 & 8,4 \\
\hline TOTAL & 6 & 50,0 & 6 & 50,0 & 100,0 \\
\hline
\end{tabular}

\section{Análise conjunta das edificações e móveis}

Considerando-se todas as quadras cujas edificações comerciais foram inspecionadas, pode-se separar as infestações em três grupos: as que apresentaram cupins tanto em peças da construção como em móveis, em número de 5 (71,4\%); as que apresentaram cupins apenas em móveis, em número de $1(14,3 \%)$ e as que apresentaram cupins somente na edificação, em número de 1 (14,3\%). Neste caso, pode-se considerar que o fato de se ter alguma peça atacada por cupins nas edificações favorece o alastramento das infestações, no entanto essa afirmação deve ser confirmada com base em maior amostragem. $\mathrm{O}$ menor número de casos de infestações por cupins nas edificações comerciais pode ser explicado pelas constantes desinsetizações. Normalmente, as desinsetizações não são específicas para cupins, mas eles podem ser descobertos no momento da inspeção prévia à desinsetização, o que contribui para a prevenção de novas infestações por térmitas.

\section{Estrato 3 - Prédios de apartamentos}

\section{Edificação}

Embora, os prédios, que apresentaram cupins estejam entre os mais antigos, não é possível afirmar que haja tendência em aumentar a probabilidade de infestações por cupins com a idade da edificação, visto que o número de amostras foi pequeno, não possibilitando que essas relações fossem feitas (Tabela 3).

TABELA 3: Distribuição das freqüências absolutas e relativas das ocorrências de cupins em prédios de apartamentos de diferentes idades.

\begin{tabular}{l|c|c|c|c|c}
\hline $\begin{array}{c}\text { Classes por idades } \\
\text { (anos) }\end{array}$ & Com cupins & $\%$ & Sem-cupins & $\%$ & Total \\
\hline $0-10$ & 0 & 0 & 6 & 100,0 & 6 \\
$11-20$ & 0 & 0 & 5 & 100,0 & 5 \\
$21-30$ & 1 & 100,0 & 0 & 0 & 1 \\
$31-40$ & 1 & 100,0 & 0 & 0 & 1 \\
\hline \multicolumn{7}{r}{} \\
\hline
\end{tabular}




\section{Móveis}

Não foram encontrados cupins em móveis das áreas comuns dos prédios de apartamentos. Esses resultados podem ser decorrentes do fato de haver baixos índices de ocorrências de cupins em prédios de apartamentos, sendo que a constante manutenção realizada pelos funcionários, não permite a permanência de focos de cupins nessas áreas, pois assim que detectados são rapidamente eliminados.

\section{Análise Conjunta das Edificações e móveis}

Os cupins encontrados nesse estratos estavam atacando somente componentes da edificação.

\section{Espécies de cupins encontradas}

O Bairro São Dimas não apresentou grande diversidade de espécies de cupins. Nas edificações residenciais e em seus móveis houve focos apenas de cupins de madeira seca, Cryptotermes brevis (Walker) (Figura 2).

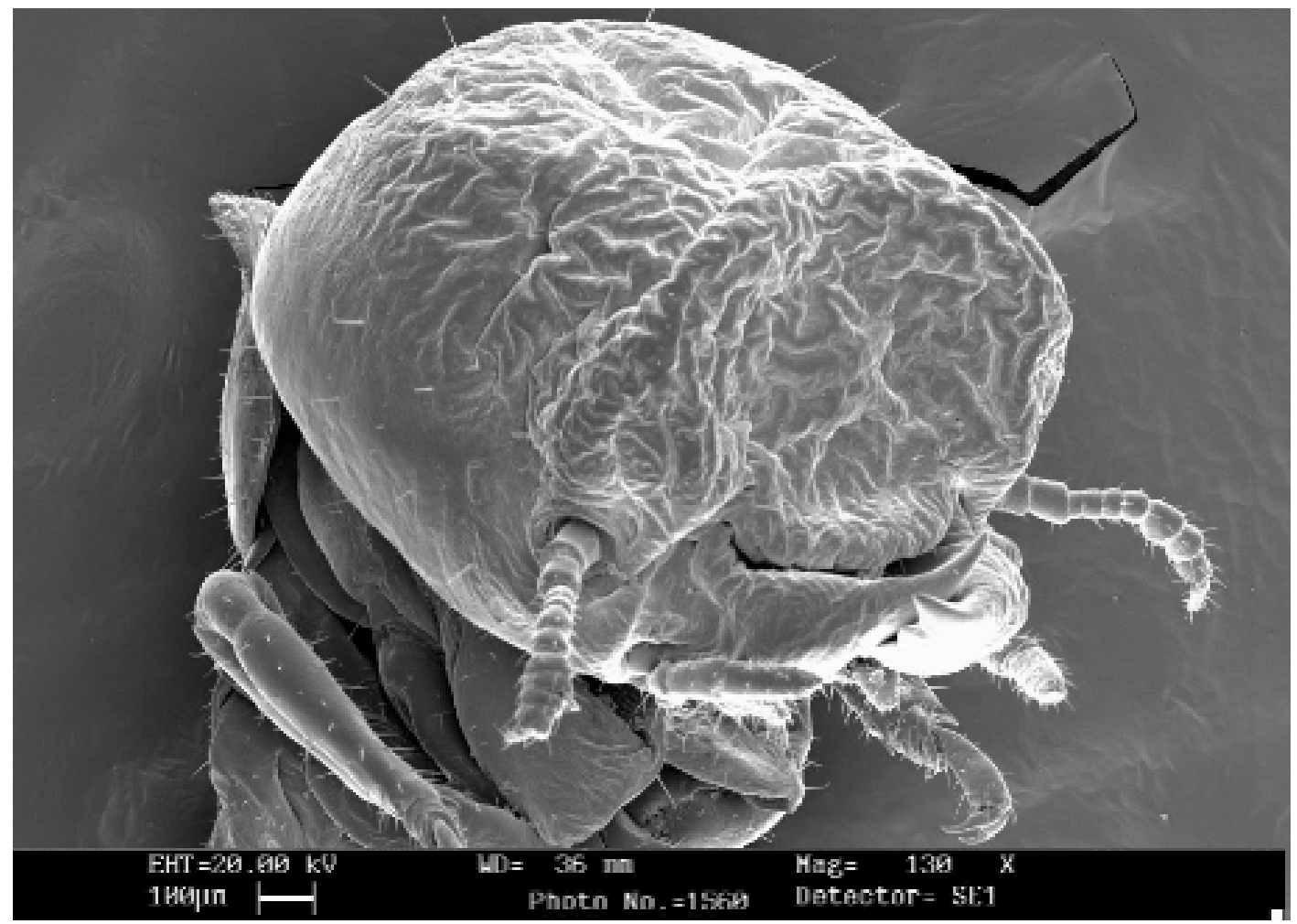

FIGURA 2: Fotografia em microscópio eletrônico de varredura de soldado de Cryptotermes brevis. As rugosidades na cabeça são características próprias da espécie. (Aumento de 130x)

Os cupins encontrados, nas edificações comerciais e em seus móveis, foram somente os de madeira seca, Cryptotermes brevis.

Em prédios de apartamentos, ocorreram cupins, apenas na edificação, sendo que estavam 
presentes a espécie de cupim de madeira seca Cryptotermes brevis e a espécie de cupim subterrâneo Coptotermes havilandi (Holmgren) (Figura 3).

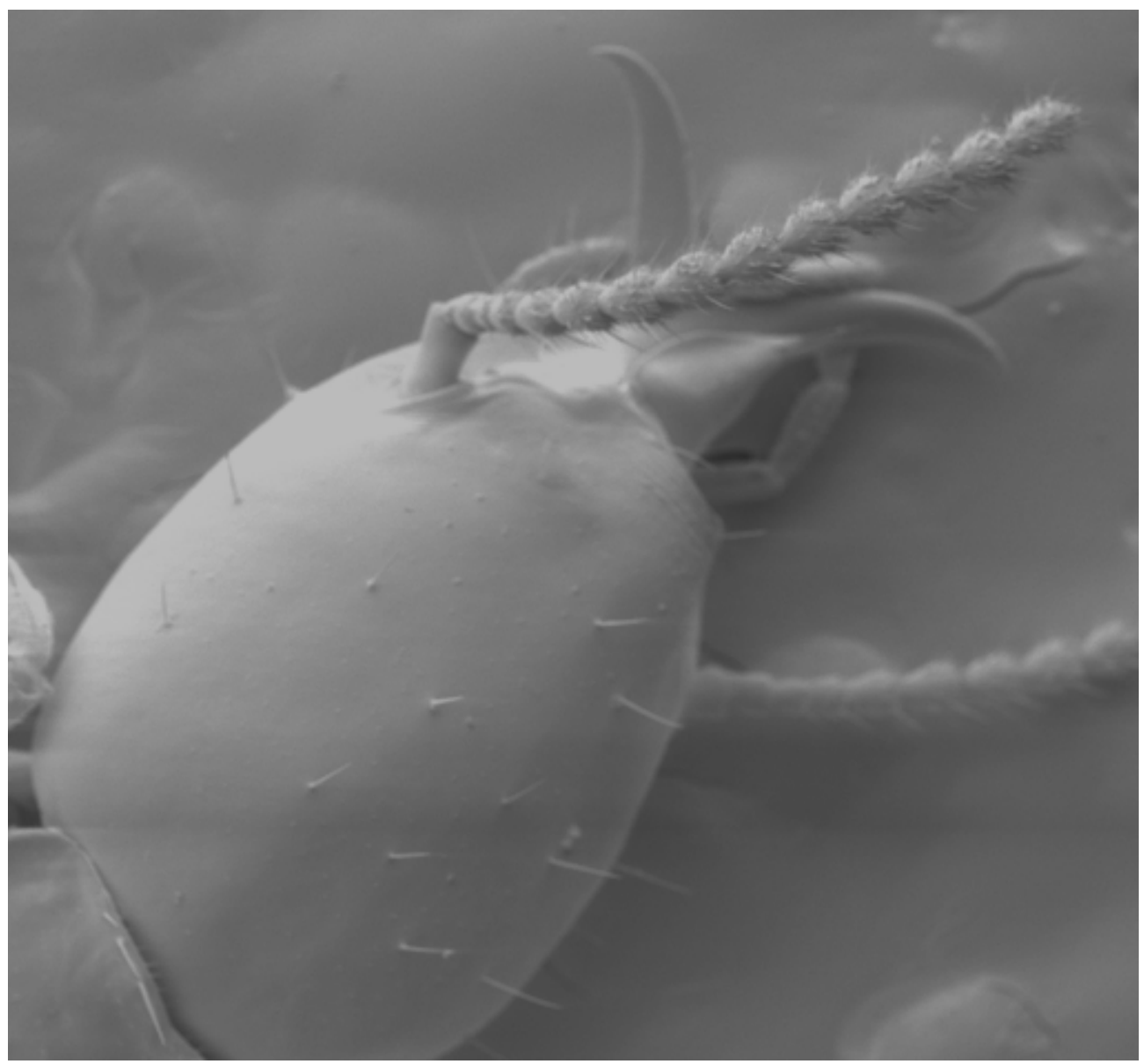

FIGURA 3: Fotografia em microscópio eletrônico de varredura de um soldado de Coptotermes havilandi (aumento de 40x).

É importante ressaltar que foram coletados espécimens de cupins de madeira seca Cryptotermes brevis em sete edificações. A coleta de cupins nem sempre foi possível em razão da necessidade de destruir-se as peças nas quais estavam as colônias. Nos demais imóveis foram coletados apenas os resíduos fecais dos cupins que estavam infestando as peças (Figura 4). Com base na análise desses resíduos, constatou-se que todos eram de cupins de madeira seca e se pode, por extrapolação, considerar que, possivelmente, eles sejam Cryptotermes brevis, pois todos os espécimens identificados no bairro eram dessa espécie.

\section{Cupins de madeira seca (Cryptotermes brevis)}

Observou-se que houve maior freqüência de cupins de madeira seca. Essa ocorrência, exclusiva de cupins de madeira seca em imóveis residenciais e comerciais, pode ser influenciada pela falta de condições favoráveis à instalação de cupins subterrâneos por causa da pequena quantidade de umidade e pelas próprias características da região que apresenta longos períodos de seca, ou do 
bairro que possui poucas áreas sombreadas e úmidas em conseqüência do reduzido número de árvores. Essas condições são consideradas, por HAAGSMA \& RUST (1995), HEDGES (1998), HOWARD et al. (1982) e RUDOLPH et al. (1990), como limitantes para a sobrevivência de cupins subterrâneos.

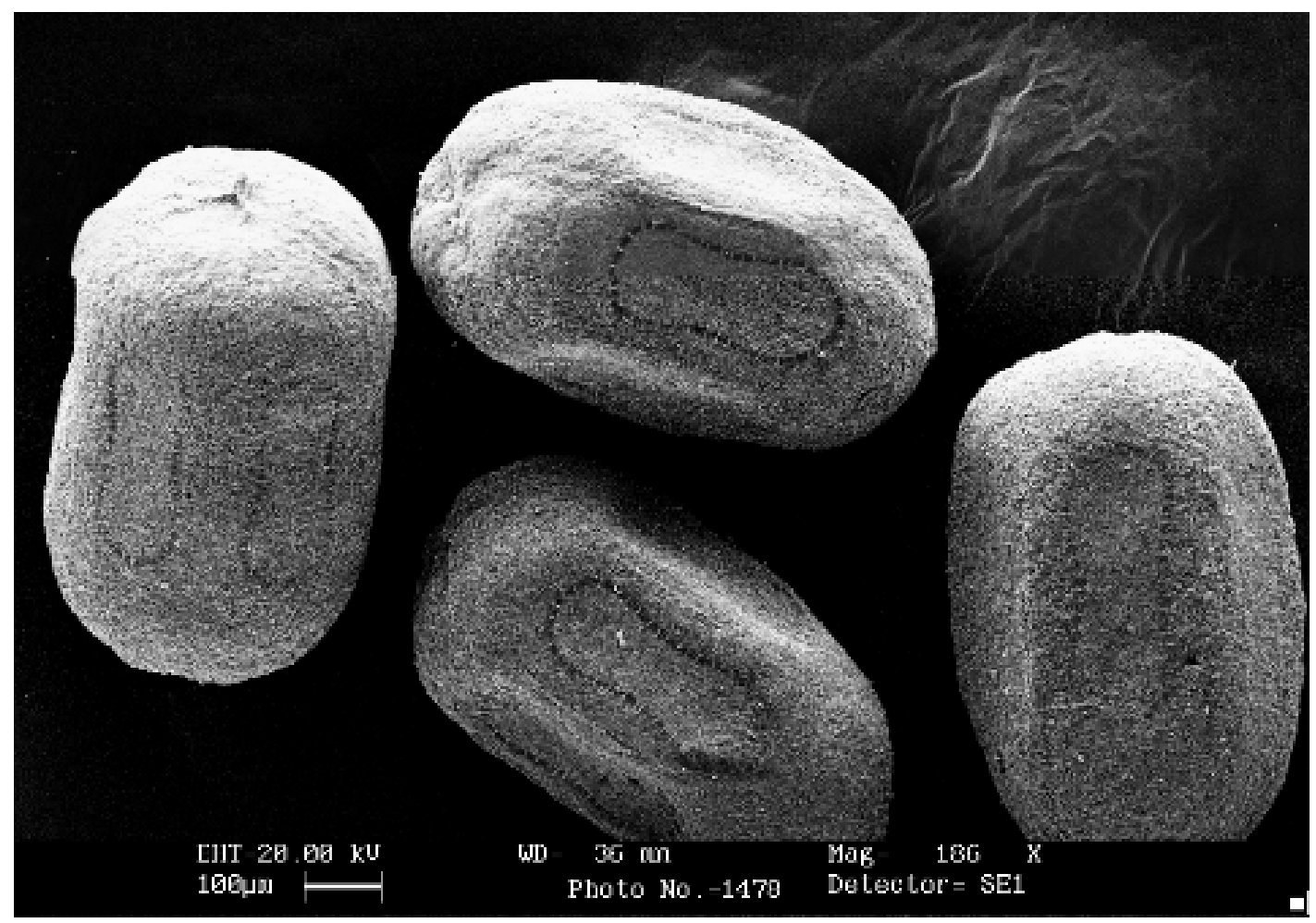

FIGURA 4: Fotografia em microscópio eletrônico de varredura de resíduos fecais de cupins de madeira seca (Cryptotermes ou Eucryptotermes). Aumento de 90x.

As condições de temperatura e umidade, da região, não influem, no entanto, no estabelecimento de cupins de madeira seca que sobrevivem longos períodos com pouca umidade e com temperaturas elevadas. Essas afirmações são concordantes com o que foi constatado por EDWARDS \& MILL (1986); WALLER \& LA FAGE (1986) e RUDOLPH et al., (1990), sobre baixo requerimento de umidade e grande tolerância às condições secas, por períodos prolongados, apresentados pelos cupins pertencentes a esse grupo. A grande resistência de Cryptotermes brevis é reforçada por BECKER (1978) que relatou a sobrevivência e desenvolvimento de colônias de cupins dessa espécie em condições de temperatura, umidade e nutrição, extremamente, desfavoráveis, em Berlim, Alemanha.

A ampla distribuição de cupins de madeira seca, nesse bairro, era um resultado esperado, frente à sua distribuição nas maiores regiões zoogeográficas do mundo. Eles são cupins considerados cosmopolitas e ocorrem com grande freqüência no ambiente doméstico (BACCHUS,1987). É importante salientar que, apesar dos cupins de madeira seca serem menos vorazes do que os cupins subterrâneos, podem causar danos expressivos às construções ao longo do tempo. No Brasil, os gêneros mais encontrados de cupins de madeira seca são Cryptotermes e Eucryptotermes (LELIS, 
1976).

\section{Cupins subterrâneos}

Foi encontrado apenas um caso de cupim subterrâneo no bairro (Coptotermes havilandi). Na cidade de São Paulo, essa espécie, de origem oriental, está bastante disseminada e causa prejuízos consideráveis (LELIS, 1994). No entanto, pode-se considerar que o Bairro São Dimas não apresenta uma infestação por cupins subterrâneos, mas é importante levar-se em conta que essa espécie se dispersa rapidamente e pode vir a causar prejuízos futuramente.

O fato, de não terem sido encontrados mais casos de cupins subterrâneos, pode ser atribuído ao tipo de clima da região de Piracicaba, com baixa precipitação pluviométrica, apenas 1.070,6mm (CIAGRI, 1999), o que não fornece condições, para a manutenção das colônias de cupins desse grupo. Segundo ROBINSON (1996), diferenças regionais de temperatura e umidade podem influenciar na distribuição dos cupins subterrâneos. Apesar do clima de Piracicaba ser desfavorável a esse cupim, é importante que se tomem medidas preventivas contra o ataque dessa espécie, pois os ambientes urbanos, mediante as atividades do homem (irrigações em jardins, água provenientes de aparelhos de ar condicionados, vazamentos de canalizações de água, etc.) podem vir a disponibilizar outras fontes de água para os cupins.

Segundo FONTES (1995), a Região Sudeste do Brasil é a mais assolada por ataques de Coptotermes havilandi. Isso sugere que Piracicaba pode vir a ser mais uma cidade da região a ter esse cupim como praga importante.

Também se deve ressaltar que o fato do bairro São Dimas ter ainda muito espaço livre e as edificações não serem muito próximas umas das outras, como nas grandes cidades, é um dos fatores limitantes à dispersão do cupim subterrâneo por dificultar a sua passagem de uma edificação para outra (LELIS 1999).

\section{Distribuição dos diferentes grupos de cupins no bairro São Dimas}

Os cupins de madeira seca estão amplamente distribuídos no bairro, sendo que nas quadras que estão mais próximas do rio Piracicaba há maior número de focos por quadra. $\mathrm{O}$ número de focos tende a diminuir nas quadras conforme fastam-se do rio. Os cupins subterrâneos ocorreram apenas na parte sul do bairro. Isso sugere que pode haver mais casos de infestação, por esse tipo de cupim, em áreas próximas.

\section{Outras considerações}

Não foram observados, neste trabalho, ataques de cupins de madeira úmida (Termopsidae). Segundo SU \& SCHEFFRAHN (1990), esses cupins atacam madeiras úmidas e já degradadas por fungos em construções de várias partes do mundo. No Brasil, LELIS (1976) relata que espécies de cupins de madeira úmida apenas foram registradas em árvores vivas, mas nunca atacando edificações.

É importante ressaltar a falta de conhecimento das pessoas sobre os cupins e sobre as 
madeiras utilizadas nas construções de imóveis. Considerando-se os proprietários ou locatários dos 52 imóveis, residenciais e comerciais, somente três pessoas $(5,8 \%)$ sabiam que as aleluias ou siriris são cupins em revoada, com fins reprodutivos e que infestam as peças de madeira e os móveis nos seus prédios. Também são confundidos os sintomas do ataque de cupins de madeira seca com os danos causados por outros organismos biodeterioradores, tais como fungos, formigas e brocas. Sobre os sintomas de ataques de cupins subterrâneos, a maior parte da população desconhece, porém, 4 zeladores de prédios de apartamentos tinham conhecimento sobre esses cupins mediante treinamentos profissionais.

A ampliação desse estudo, para outros bairros da cidade de Piracicaba, seria interessante, pois proporcionaria maiores conhecimentos sobre a dispersão das espécies de cupins e os fatores que a influenciam.

\section{CONCLUSÕES}

O risco de infestações por cupins, em residências, aumenta com a idade das edificações.

O número de focos de cupins, nas edificações residenciais, tende a aumentar com a idade das construções. Em edificações comerciais e em prédios de apartamentos esta relação não é clara.

Em edificações residenciais a presença de cupins não implica necessariamente na sua presença nos móveis e vice-versa.

Há pouco conhecimento, por parte da população, sobre a problemática dos cupins em edificações e há confusão entre os sintomas do ataque de cupins e de outros organismos biodeterioradores.

\section{AGRADECIMENTOS}

Ao Dr. Luiz Roberto Fontes (SUCEN/SP), pela identificação dos cupins.

Ao Núcleo de Apoio à Pesquisa em Microscopia Eletrônica Aplicada a Agricultura/ESALQ/USP (NAP/MEPA), onde foram realizados os exames dos cupins em microscópio eletrônico de varredura.

\section{REFERÊNCIAS BIBLIOGRÁFICAS}

ARAUJO, R.L. Térmitas prejudiciais às madeiras. In: MARICONI, F. A .M.; ZAMITH, A. P. L.; ARAÚJO, R.L. et. al. (Eds.).Inseticidas e seu emprego no combate às pragas. São Paulo: Nobel, 1980. p.100-123.

BACCHUS, S. A taxonomic and biometric study of the genus Cryptotermes (Isoptera, 
Kalotermitidae). Tropical Pest Bulletin, n.7, p.1-91, 1987.

BANDEIRA, A. G. Análise da termitofauna (Insecta: Isoptera) de floresta primária e de pastagem da Amazônia Oriental, Brasil. Boletim do Museu Paraense Emílio Goeldi, Zoologia, v.5, n.2, p.225-242, 1989.

CIAGRI. Centro de Informática do Campus Luiz de Queiroz. Aspectos físicos da Cidade de Piracicaba, SP. [online]. Piracicaba: USP, 1999. Available from www:<URL: http://www. ciagri.usp.br/piracica/aspfis-p.htm>

BECKER, G. On termites in Central and South America. Revista Floresta, v.9, n.2, p.71-75, 1978.

EDWARDS, R.; MILL, A. E. Termites in buildings: their biology and control. Felcourt: Rentokil, 1986. 231p.

FONTES, L. R. Termites (Isoptera) que causam infestación en Brasil. In: BERTI FILHO, E. (Ed.); FONTES, L. R. (Ed.). Alguns aspectos atuais da biologia e controle de cupins. Piracicaba: FEALQ, 1995. p.163-164.

GOLD, R. E.; HOWELL, H. N.; PAWSON, B. M. et al. Persistence and bioavailability of termiticides to subterranean termites (Isoptera: Rhinotermitidae) from five soil types and locations in Texas. Sociobiology, n.28, p.337-363, 1996.

GRASSÉ, P.P. Termitologia. Paris: Masson, 1982. v. 1.

HAAGSMA, K. A.; RUST, M. K. Colony size estimates, foraging trends, and physiological characteristics of the western subterranean termite (Isoptera: Rhinotermitidae). Entomological Society of America, v.24, n.6, p.1520-1528, Dec. 1995.

HARRIS, W. V. Termites: their recognition and control. England: Longman Group, 1971. 186p.

HEDGES, S. Add-on for termite control. Pest Control Technology, p.30-35, Feb. 1998.

HOWARD, R. W.; JONES, S. C.; MAULDIN, J. K. et al. Abundance, distribution and colony size estimates for Reticulitermes spp. (Isoptera: Rhinotermitidae) in southern Mississippi. Environmental Entomology, v.11, n.6, p.1920-1293, Dec. 1982.

LELIS, A. T. Cupins: prevenção e erradicação. Preservação de Madeiras, v.6-7, n.1, p.51-58, 1976.

. Termite problem in São Paulo City - Brazil. In:CONGRESS OF THE INTERNATIONAL UNION FOR THE STUDY OF SOCIAL INSECTS, 12., 1994, Sorbone. Proceedings ... Paris: Sorbone, 1994. p.253.

. Cupins urbanos: biologia e controle. In: BERTI FILHO, E.; FONTES, L. R. (Eds.). Alguns Aspectos atuais da biologia e controle de cupins. Piracicaba: FEALQ, 1995. p.77-80.

Imaginal and neotenic queens of Coptotermes havilandi (Isoptera, Rhinotermitidae) from São Paulo, Brazil: The implication of supplemental reproductives in termite control. In: CONGRESS OF THE INTERNATIONAL UNION FOR THE STUDY OF SOCIAL INSECTS, 13., Adelaide. Proceedings ... Adelaide, 1999. p. 234. 
MARER, P. Residential industrial pestcontrol. [online]. Oakland: University Californial, Agriculture and Natural Resourses, Publication 3334. Available from www:<URL: http:// www.ipm.ucdavis.edu/PMG/PESTNOTES>.

MARICONI, F. A. M.; ZAMITH, A. P.; ARAUJO, R. L. et al. Inseticidas e seu emprego no combate às pragas. São Paulo: Nobel, 1980. v. 3.

OLIVEIRA, A. M. F.; LELIS, A. T. de; LEPAGE, E. S. et al. Agentes destruidores da madeira. In: LEPAGE, E. S. (Coord.). Manual de preservação de madeiras. São Paulo: IPT, 1986. v.I, p.99-278.

ROBINSON, W. H. Urban entomology: insect and mite pests in the human environment. London: Chapman \& Hall, 1996. 72 p.

RUDOLPH, D; GLOCKE, B.; RATHENOW, S. On the role of different humidity parameters for the survival, distribution and ecology of various termite species. Sociobiology, v.17, n.1, p.129$140,1990$.

STEWARD, R. C. Microclimate and colony foundation by imago and neotenic reprodutives of drywood temite species (Cryptotermes sp.) (Isoptera: Kalotermitidae). Sociobiology, v.7, n.3, p.311-331, 1983.

SU, N-Y.; SCHEFFRAHN, R. H. Economicaly important termites in the United States an their control. Sociobiology, v.17, n.1, p.77-94, 1990.

WALLER, D. A.; LA FAGE, J. P. Nutritional ecology of termites. In: SLANSKY JR., F.; RODRIGUEZ, J. C. Nutritional ecology of insects, mites, spiders and related invertebrates. New York: Wiley-Interscience Publication, 1986. Cap.16, p.487-532. 